\title{
The Role of Hepatic Ischemia-Reperfusion Injury and Liver Parenchymal Quality on Cancer Recurrence
}

\author{
Lorenzo A. Orci · Stéphanie Lacotte • \\ Graziano Oldani · Philippe Morel • \\ Gilles Mentha $\cdot$ Christian Toso
}

Received: 13 March 2014/ Accepted: 20 April 2014/Published online: 3 May 2014

(C) Springer Science+Business Media New York 2014

\begin{abstract}
Hepatic ischemia/reperfusion (I/R) injury is a common clinical challenge. Despite accumulating evidence regarding its mechanisms and potential therapeutic approaches, hepatic $\mathrm{I} / \mathrm{R}$ is still a leading cause of organ dysfunction, morbidity, and resource utilization, especially in those patients with underlying parenchymal abnormalities. In the oncological setting, there are growing concerns regarding the deleterious impact of $\mathrm{I} / \mathrm{R}$ injury on the risk of post-surgical tumor recurrence. This review aims at giving the last updates regarding the role of hepatic I/R and liver parenchymal quality injury in the setting of oncological liver surgery, using a "bench-to-bedside" approach. Relevant medical literature was identified by searching PubMed
\end{abstract}

\author{
L. A. Orci $(\bowtie) \cdot$ S. Lacotte $\cdot$ G. Oldani · P. Morel · \\ G. Mentha $\cdot$ C. Toso $(\bowtie)$ \\ Division of Abdominal and Transplantation Surgery, Department \\ of Surgery, Geneva University Hospitals and Faculty of \\ Medicine, University of Geneva, 4 rue Gabrielle-Perret-Gentil, \\ 1211 Geneva, Switzerland \\ e-mail: lorenzo.orci@hcuge.ch \\ C. Toso \\ e-mail: christian.toso@hcuge.ch \\ S. Lacotte \\ e-mail: stephanie.lacotte@unige.ch \\ G. Oldani \\ e-mail: Graziano.oldani@hcuge.ch \\ P. Morel \\ e-mail: Philippe.morel@hcuge.ch \\ G. Mentha \\ e-mail: Gilles.mentha@hcuge.ch
}

L. A. Orci - G. Oldani · P. Morel · G. Mentha - C. Toso

Hepato-Pancreato-Biliary Centre, Geneva University Hospitals and Faculty of Medicine, University of Geneva, 4 rue

Gabrielle-Perret-Gentil, 1211 Geneva, Switzerland and hand scanning of the reference lists of articles considered for inclusion. Numerous preclinical models have depicted the impact of $\mathrm{I} / \mathrm{R}$ injury and hepatic parenchymal quality (steatosis, age) on increased cancer growth in the injured liver. Putative pathophysiological mechanisms linking $\mathrm{I} / \mathrm{R}$ injury and liver cancer recurrence include an increased implantation of circulating cancer cells in the ischemic liver and the upregulation of proliferation and angiogenic factors following the ischemic insult. Although limited, there is growing clinical evidence that $I / R$ injury and liver quality are associated with the risk of post-surgical cancer recurrence. In conclusion, on top of its harmful early impact on organ function, $\mathrm{I} / \mathrm{R}$ injury is linked to increased tumor growth. Therapeutic strategies tackling I/R injury could not only improve post-surgical organ function, but also allow a reduction in the risk of cancer recurrence.

Keywords Ischemia-reperfusion injury - Liver steatosis · Hepatocellular carcinoma · Hepatectomy $\cdot$ Liver transplantation

\section{Introduction}

Ischemia-reperfusion (I/R) injury is a process whereby parenchymal damage caused by blood flow deprivation is accentuated upon organ reperfusion. I/R injury is a common clinical challenge, as it arises in various clinical scenarios such as cerebrovascular disease [1], circulatory shock [2], cardiovascular [3] and liver surgery [4], and transplantation medicine $[5,6]$. I/R injury, through the liberation of radical oxygen species and the activation of inflammatory pathways, induces cellular injury and microcirculatory damage, which translate to organ dysfunction, morbidity, and increased health care costs $[7,8]$. In 
the liver, I/R injury is at the source of poor outcomes after surgical procedures such as hepatectomy and liver transplantation [7].

Lowering intraoperative blood loss during hepatectomy is a crucial factor determining the success of liver resection, as surgical bleeding and transfusion are associated with poor outcomes in both the short- and long term [911]. Thus, liver surgeons have the option to apply vascular inflow control procedures and sometimes total vascular exclusion to reduce intraoperative bleeding. The major drawback of such strategies is that they can induce I/R injury to the residual liver parenchyma [4, 12]. In liver transplantation, tissue damage at reperfusion is mostly correlated with warm and cold ischemia times and leads in turn to poor graft function [13] and biliary complications $[14,15]$.

In addition to the direct I/R-mediated harmful effect on the liver parenchyma, underlying organ physiology and the presence of pre-established tissue lesions (e.g., steatosis) interact with I/R injury [16]. Hepatic steatosis increases susceptibility of the liver to I/R injury through microcirculatory dysfunction caused by sinusoid compression by lipid droplets [17-19] and reduced cellular energy stock and cell membrane disruption via I/R-mediated lipid peroxidation [20]. Moreover, aged livers also appear to be less tolerant to I/R injury [21]. This is particularly relevant to the transplantation setting, where the use of marginal donors, such as (macro-) steatotic graft or livers from older donors, has been shown to be associated with poorer outcomes after liver transplantation [22, 23].

Besides jeopardizing patients' outcome in the early postoperative period, there are growing concerns surrounding the role of hepatic I/R injury and surgical trauma in the oncological setting. Surgical manipulation of the liver induces the release of cancer cells in the blood stream, which could in turn engraft into the remnant liver or into the newly transplanted liver graft and constitute the source of tumor recurrence [24, 25]. I/R injury induces the expression of cytokines, growth factors, and adhesion molecules that have been repeatedly reported to foster tumor growth [2628]. The aim of this review was to give the last updates regarding the role of hepatic $\mathrm{I} / \mathrm{R}$ injury with regard to oncological outcomes, focusing on experimental models used to assess this issue, clinical evidence, and potential therapeutic strategies aimed at reducing the risk of I/Rmediated post-surgical tumor recurrence. Both the settings of liver resection and transplantation will be explored.

\section{Methods}

The design of the current manuscript consists of a narrative (non-systematic) review. Of note, systematic reviews of experimental studies are feasible [29] and may help answer a specific research question. Despite such a design would have been a possibility, the multiple settings and research questions (liver resection: pedicle vs. no pedicle clamping, hemi-vascular occlusion, therapeutic strategies; liver transplantation: donation after cardiac death, small-forsize) that were aimed to be addressed here fostered us to undertake a narrative review. A literature search was performed in Medline, using the following keywords: ischemia-reperfusion, steatosis, small-for-size, liver cancer, hepatocellular carcinoma, colorectal metastases, colon adenocarcinoma, and tumor growth. Only studies written English and published in peer-reviewed journals were considered for inclusion. Studies were categorized according to their research design (experimental, clinical retrospective, and clinical prospective). Study eligibility for inclusion was based on their ability to provide composite insight into the link between liver parenchyma and cancer behavior and to guide the reader to relevant primary and secondary sources for further reading.

\section{Discussion}

\section{Preclinical Evidence}

\section{Hepatic Ischemia-Reperfusion Injury Enhances Hepatic Tumor Growth}

There are reports dating back to the 1960 s where ischemic tissue was observed to offer a favorable environment for the implantation and growth of blood-borne metastases [30, 31]. In the liver, to evaluate the link between hepatic I/R injury and cancer behavior, research groups have used several hepatic I/R injury models complemented with the inoculation of different tumor cell lineages (Table 1). In a rat colon adenocarcinoma metastasis model, Kurata et al. [32] showed that, compared to sham-operated animals, 30-min partial (median and left lobes) ischemia to the liver induced a 14-fold increase in the number of metastatic nodules $(p<0.01)$. Using a mouse colon adenocarcinoma model, Gorden et al. reported similar findings, with an increase in both the number of nodules and tumor volume in animals undergoing a 30-min course of $70 \%$ ischemia (via clamping of the median and left lobes) [33]. In another experiment using a hepatocellular carcinoma (HCC) cell line, Man et al. [34] observed markedly higher tumor growth and invasiveness in those animals subjected to a 60 -min period of ischemia followed by $60 \mathrm{~min}$ of reperfusion as compared to sham-operated animals. Several other preclinical reports [35-38] explored the impact of hepatic I/R injury on tumor growth and metastatic potential, as illustrated in Table 1. 
Table 1 Ischemia-reperfusion injury fosters liver metastases, experimental models

\begin{tabular}{|c|c|c|c|c|}
\hline Doi [40] & Rat & 30 versus $60 \min 70 \%$ ischemia & $\begin{array}{l}\text { Colon } \\
\text { adenocarcinoma } \\
(\mathrm{RCN}-\mathrm{H} 4)\end{array}$ & $\begin{array}{l}\uparrow \text { E-selectin in liver tissue of ischemic groups } \\
\text { compared to control }\end{array}$ \\
\hline Doi [35] & Rat & $60 \min 70 \%$ ischemia & $\begin{array}{l}\text { Colon } \\
\text { adenocarcinoma } \\
(\mathrm{RCN}-\mathrm{H} 4)\end{array}$ & $\begin{array}{l}\text { Administration of neutrophil elastase inhibitor } \\
\text { (ONO-5046) after I/R reduced the number of } \\
\text { hepatic metastases }\end{array}$ \\
\hline $\begin{array}{l}\text { Yoshida } \\
\text { [37] }\end{array}$ & Rat & $\begin{array}{l}\text { Continuous: } 60 \mathrm{~min} 70 \% \text { ischemia } \\
\text { Intermittent: } 15 \text { min periods of } 70 \% \\
\text { ischemia }(4 \times) \text {, with } 15 \text { min of } \\
\text { reperfusion between ischemia }\end{array}$ & $\begin{array}{l}\text { Colon } \\
\text { adenocarcinoma } \\
(\mathrm{RCN}-\mathrm{H} 4)\end{array}$ & $\begin{array}{l}\downarrow \text { E-selectin in liver tissue of the intermittent } \\
\text { ischemia group compared to continuous ischemia }\end{array}$ \\
\hline $\begin{array}{l}\text { Van der } \\
\text { Bilt [62] }\end{array}$ & Mouse & $\begin{array}{l}\text { Continuous: } 45 \text { min } 40 \% \text { ischemia } \\
\text { Intermittent: } 15 \text { min periods o } 40 \% \\
\text { ischemia }(\times 3) \text {, with } 5 \text { min of reperfusion } \\
\text { between ischemia } \\
\text { Ischemic pre-conditioning: } 10 \mathrm{~min} 40 \% \\
\text { ischemia, followed by } 15 \text { min of } \\
\text { reperfusion, before } 45 \text {-min } 40 \% \\
\text { ischemia }\end{array}$ & $\begin{array}{l}\text { Colon } \\
\text { adenocarcinoma } \\
(\mathrm{C} 26)\end{array}$ & $\begin{array}{l}\text { Accelerated tumor growth localized around necrotic } \\
\text { tissue areas. Ischemic lobes show lowered levels } \\
\text { of glutathione compared to non-ischemic lobes }\end{array}$ \\
\hline Kurata [32] & Rat & $\begin{array}{l}30 \min 70 \% \text { ischemia followed by } \\
\text { resection of non-ischemic lobes }\end{array}$ & $\begin{array}{l}\text { Colon } \\
\text { adenocarcinoma } \\
(\mathrm{RCN}-\mathrm{H} 4)\end{array}$ & $\begin{array}{l}\text { Antithrombin inhibited the increase in the number } \\
\text { of metastatic nodules in animals subjected to I/R } \\
\text { injury, by blunting the TNF- } \alpha \text {-induced expression } \\
\text { of E-selectin, through an increase in endothelial } \\
\text { PGI }_{2} \text { production }\end{array}$ \\
\hline Man [34] & Rat & $\begin{array}{l}60 \min 60 \% \text { ischemia } \\
60 \text { min } 60 \% \text { ischemia plus major } \\
\text { hepatectomy }\end{array}$ & $\begin{array}{l}\text { Hepatoma (MCA- } \\
\text { RH7777) }\end{array}$ & $\begin{array}{l}\uparrow \text { Proliferation (PCNA staining) of tumor cells and } \\
\text { VEGF in the ischemic group, } \uparrow \text { invasiveness } \\
\text { genetic profile (expression of ROCK and Cdc- } 42 \text { ) } \\
\text { in animals receiving both I/R and hepatectomy }\end{array}$ \\
\hline $\begin{array}{l}\text { Van der } \\
\text { Bilt [82] }\end{array}$ & Mouse & $45 \min 40 \%$ ischemia & $\begin{array}{l}\text { Colon } \\
\text { adenocarcinoma } \\
(\mathrm{C} 26)\end{array}$ & $\begin{array}{l}\text { I/R injury-mediated tumor growth occurs } \\
\text { preferentially in areas of tissue hypoxia, and } \\
\text { elevated HIF-1 } \alpha \text { expression } \\
\text { HIF-1 } \alpha \text { was detected in nuclei of tumor cells at the } \\
\text { tumor-necrosis margin in the ischemic group } \\
\text { Attenuation of microcirculatory damage, hypoxia } \\
\text { and hepatocellular damage by atrasentan/L- } \\
\text { arginine allows a reduced tumor outgrowth }\end{array}$ \\
\hline $\begin{array}{c}\text { Nicoud } \\
{[33]}\end{array}$ & Mouse & $30 \min 70 \%$ ischemia & $\begin{array}{l}\text { Colon } \\
\text { adenocarcinoma } \\
\text { (MC38) }\end{array}$ & $\begin{array}{l}\uparrow \text { MMP9 mRNA and protein expression in liver } \\
\text { tissue of ischemic group } \\
\text { Doxycycline inhibits I/R-induced MMP9, and } \\
\text { decreases hepatic metastases } \\
\text { Genetic deletion of MMP9 prevents hepatic } \\
\text { metastases }\end{array}$ \\
\hline $\begin{array}{l}\text { Van der } \\
\text { Bilt [39] }\end{array}$ & Mouse & $\begin{array}{l}\text { Ischemia time: } 20 \text { min versus } 30 \mathrm{~min} \\
\text { versus } 45 \mathrm{~min} 40 \% \text { ischemia } \\
\text { Steatosis: } 6 \text {-week high-fat diet versus } \\
\text { normal diet } \\
\text { Age: } \text { Adult mice (12-13 months) versus } \\
\text { 10-12 weeks } \\
\text { Gender: male versus female }\end{array}$ & $\begin{array}{l}\text { Colon } \\
\text { adenocarcinoma } \\
(\mathrm{C} 26)\end{array}$ & $\begin{array}{l}\text { Steatosis and male gender lead to heightened I/R- } \\
\text { mediated tumor outgrowth }\end{array}$ \\
\hline $\begin{array}{l}\text { Tamagawa } \\
{[36]}\end{array}$ & Rat & $60 \min 70 \%$ ischemia & $\begin{array}{l}\text { Colon } \\
\text { adenocarcinoma } \\
(\mathrm{RCN}-\mathrm{H} 4)\end{array}$ & $\begin{array}{l}\uparrow \text { Plasma and liver tissue VEGF in the ischemic } \\
\text { group compared to control }\end{array}$ \\
\hline $\begin{array}{l}\text { Yoshimoto } \\
{[38]}\end{array}$ & $\begin{array}{l}\text { Nude } \\
\text { mouse }\end{array}$ & 20-min total ischemia & $\begin{array}{l}\text { Human pancreatic } \\
\text { cancer (Capan- } \\
\text { 1) }\end{array}$ & $\begin{array}{l}\uparrow \text { E-selectin in liver tissue of the ischemic group } \\
\text { compared to control }\end{array}$ \\
\hline
\end{tabular}

I/R ischemia/reperfusion, VEGF vascular endothelial growth factor, MMP-9 matrix metalloproteinase-9, $H I F-1 \alpha$ hypoxia-inducible factor $1 \alpha$, $P C N A$ proliferating cell nuclear antigen, $P G I_{2}$ prostaglandin $\mathrm{I}_{2}, R O C K$ Rho-associated protein kinase, $C d c-42$ cell division control protein 42 homolog 
Looking at the impact of duration of ischemia on $\mathrm{I} / \mathrm{R}$ injury-mediated metastasis development, van der Bilt et al. reported significant differences in terms of hepatic metastases growth according to the duration of warm ischemia. Mice subjected to 20 min of ischemia had a similar tumor burden compared to non-ischemic liver tissue (shamoperated animals or non-clamped liver lobes). In contrast, after 30 and $45 \mathrm{~min}$ of ischemia, mice had a significantly increased tumor burden compared to non-ischemic controls [39]. In the same way, Doi et al. observed that rats undergoing 60-min segmental $(70 \%)$ hepatic ischemia developed significantly more nodules than rats subjected to 30-min pedicle clamping. Contrasting with the findings by the Utrecht group that observed a five- to sixfold accelerated tumor outgrowth in the ischemic liver as compared to non-occluded lobes, Doi et al. reported that I/R injury leads to increased tumor growth in all liver lobes (even the nonclamped lobes), suggesting a dissemination of the effect of I/R injury to liver tissue not directly enduring parenchymal damage [40]. Although apparently self-contradictory, these differences could be linked to several divergences in the models used. First, the experiments were undertaken in two different animal models (rat [40] vs. mouse [39]) reminding that pathophysiological pathways may differ according to the species under investigation. Second, the sequence of procedures applied in these two studies were not strictly comparable: while Doi et al. [40] inoculated cancer cells in the spleen after 60 min of reperfusion, van der Bilt et al. [39] allowed pre-inoculated cells to circulate for 5 days before the induction of I/R injury. Based on these observations, one could speculate that variability in terms of cancer cell concentration in the portal system (markedly more increased after an intrasplenic bolus administered following $60 \mathrm{~min}$ of reperfusion [40] than after a 5-daylong homogeneous dilution in the blood stream [39]), could affect their implantation in the liver. Altogether, regardless of heterogeneity in the experimental models used, there is accumulating experimental evidence uniformly reporting $\mathrm{I} / \mathrm{R}$ injury to be associated with increased hepatic metastatic potential and increased tumor growth (Table 1).

\section{The Impact of Liver Resection and Small-for-Size Livers on Tumor Behavior}

The association between partial liver resection and increased metastases growth was originally described in the semantic experiments by Fisher and colleagues in the 1950s, where rats undergoing partial hepatectomy (70\%) were threefold more likely to develop liver metastases after intraportal cancer cell injection as compared to controls [41]. Since then, numerous research groups have confirmed that hepatic resection induced by itself increased tumor recurrence [42-47]. The two pivotal components of post- resection tumor recurrence (the engraftment of circulating cancer cell and the increased tumor growth of micrometastases) were thoroughly reviewed by de Jong et al. [48]. More recently, insufficient post-hepatectomy remnant liver parenchyma, referred to as small-for-size syndrome, has been evaluated as a determinant of tumor recurrence [34]. On top of being a potential cause of post-operative liver failure and a common clinical challenge in liver surgery [49, 50], small-for-size syndrome causes acute phase mechanical injury, which induces lesions similar to those observed in hepatic I/R injury [51, 52]. Therefore, smallfor-size liver models have been used to assess the relationship between parenchymal injury and circulating tumor cell engraftment. Man and co-workers evaluated the invasiveness and cell migration pathways of intraportally injected HCC cells in rats undergoing major hepatectomy (left and caudate lobes, 50-60\% of total liver volume) with or without $60-\mathrm{min}$ ischemia and 60 -min reperfusion to the right and median lobes (40-50\% of total liver volume) [34]. This experiment showed not only that small-for-size injury increases tumor growth by itself, but also that I/R injury of the liver remnant leads to increased tumor aggressiveness and metastatic potential (both intra- and extra-hepatic) [34]. Going one step further, rat tumor tissue harvested from original livers was re-implanted in the livers of nude mice undergoing different surgical stress conditions (major hepatectomy alone, I/R injury alone, I/R injury and major hepatectomy, and sham). This unique experimental design allowed demonstrating that the surgical stress resulting from hepatic I/R injury and/or major hepatectomy not only makes the hepatic microenvironment favorable for tumor cell growth, migration, and invasion through stimulation of acute phase inflammatory response and disturbance of microcirculatory barrier function, but it also makes the tumor cells more aggressive by directly activating cell migration and invasion pathways [34].

In addition to its impact on the remnant liver after hepatectomy, small-for-size syndrome is a frequent scenario affecting graft function in the transplantation setting. Small-for-size injury has been pointed out as a potential mediator of post-liver transplantation tumor recurrence. Thus, to export the evidence gathered from the liver resection setting, Man et al. [53] analyzed, in a rat liver transplantation model, the effect of small-for-size injury (achieved by removal of the left and caudate liver lobes) on post-liver transplantation tumor growth. Animals receiving small-for-size livers experienced early endothelial injury, and sinusoidal damage, followed by parenchymal necrosis and sinusoidal microthrombi, characterizing the role of small-for-graft size injury. Hepatic replacement area by circulating HCC cells was significantly increased in the small-for-size group compared to the whole liver group. To assess the stimulation of I/R injury on tumor invasiveness, 
Man et al. [53] used again an orthotopic xenogeneic tumor model, harvesting tumor tissue grown in rat liver grafts and implanting it in the liver of nude mice. Six weeks postimplantation, tumors arising from the small-for-size graft group reached higher tumor volumes and developed more distant metastases. These findings show that on top of damaging graft function, acute phase $\mathrm{I} / \mathrm{R}$ injury promotes late phase tumor growth and invasiveness.

Although the use of marginal liver grafts, including from donation after cardiac death (DCD), has been shown to be a reasonable option in the face of organ shortage, marginal grafts are more susceptible to I/R injury [54]. The current authors have shown that I/R lesions associated with rat liver transplantation from DCD donors lead to increased post-transplant HCC recurrence and growth [55]. Moreover, looking at potential therapeutic strategies, it could be demonstrated that the use of normothermic reperfusion modalities allows a reduction in $\mathrm{I} / \mathrm{R}$ lesions, and in turn of post-transplant HCC recurrence and growth, restoring HCC tumor volume to the level of non-ischemic, control animals [55].

\section{Clinical Implications}

\section{Liver Resection}

The impact of vascular inflow control procedures on the risk of cancer recurrence after liver surgery has been evaluated in a limited number of clinical studies. Nijkamp et al. have shown that severe ischemia, defined as a continuous portal triad clamping for more than 20-min or more than three cycles of 15 -min intermittent clamping, was associated with increased cancer relapse rates after liver resection for colorectal metastases [adjusted hazard ratio $(\mathrm{HR})=1.37(95 \%$ CI 1.02-1.85), $p=0.038$ ] [56]. In contrast, Giuliante et al. [57] observed no difference in terms of hepatic recurrence rate according to the use, type, and duration of hepatic pedicle clamping [57]. In another recent retrospective series including 386 patients undergoing hepatectomy for HCC with $(n=224)$ or without $(n=162)$ pedicle clamping, Xia et al. [58] reported no difference between study groups in terms of 1-, 3-, and 5 -year disease-free or overall survival. The overall recurrence rate was $67 \%$ (66.1 and $67.3 \%$ for patients with or without pedicle clamping, $p=0.828$ ), with a median time to recurrence of 26 months. Intra- versus extra-hepatic recurrence was also comparable between study groups [58]. A long-term analysis of a randomized clinical trial assessed the role of Pringle maneuver on post-resection colorectal liver metastases recurrence and did not detect differences between those undergoing vascular inflow control or not [overall survival at 1, 3, and 5 years, portal clamping group: $100,86.1$, and $49.4 \%$ vs. no clamping group: 92.6, 65.8, and 48.2 \% $(p=0.704)$ ] [59]. Diseasefree survival was also similar between the two groups: 1-, 3 - and 5-year survival rates were 85.7, 51.4, and $34.3 \%$ in the HPC group versus $84,51.5$, and $37.9 \%$, respectively $(p=0.943)$. Although these data arise from a prospective randomized study, between-group follow-up differences [median follow-up was $67.1 \pm 20$ months in the Pringle maneuver group versus $77.5 \pm 16.6$ months in the control group $(p=0.07)]$ and the small sample size represent shortcomings to this secondary analysis [59]. A recent meta-analysis did not detect any pooled difference in terms of intra-hepatic recurrence, disease-free survival, or overall survival between patients undergoing liver resection for colorectal metastases with or without pedicle clamping [60]. A prospective randomized study evaluating the effect of the Pringle maneuver on the risk of post-hepatectomy recurrence is currently ongoing [61]. This trial should shed the light on an unresolved issue and will help determining whether findings of experimental studies translate to the clinical setting.

In contrast to preclinical models that showed intermittent portal clamping as an efficacious means of reducing $\mathrm{I} / \mathrm{R}$ injury-mediated tumor growth in the rodent [37, 62], the evidence supporting the benefit of intermittent pedicle clamping on tumor behavior remains very limited in the clinical setting. In a large retrospective analysis of 563 patients undergoing liver resection for colorectal metastases, Wong et al. [63] did not find any significant difference in terms of disease-free survival between those receiving intermittent pedicle clamping or not. Of note, there was a large variability in the duration of vascular occlusion (2-104 min, median $22 \mathrm{~min}$ ), which could have led to a dilution effect between study groups, limiting the generalizability of these findings [63].

In a retrospective analysis comparing selective and total portal vein occlusion in 86 patients undergoing curative hepatectomy for HCC found, Makino et al. [64] reported a significantly longer recurrence-free survival for patients subjected to selective portal vein occlusion $(1,520$ vs. 561 days, $p=0.017$ ) in univariate analysis. After adjusting for vascular invasion and number of HCC nodules, the difference was of borderline significance $[\mathrm{HR}=1.82$ (95\% CI 0.996-3.32), $p=0.052$ ] [64].

Because $75 \%$ of liver blood flow that carries only $20-30 \%$ of oxygen runs into the portal vein, it could be argued that maintaining arterial blood flow while clamping the portal vein only may reduce intraoperative blood loss while minimizing I/R injury. Based on these observations, Yang and co-workers performed a nested case-control study evaluating the impact of portal vein occlusion with maintenance of arterial flow (vs. complete portal triad occlusion) on the risk of post-hepatectomy HCC recurrence [65]. In this cohort of 169 patients, compared to those in 
whom arterial blood flow was left untouched $(n=51)$, patients undergoing combined arterial and portal blood flow occlusion ( $n=118$ ) experienced a significantly lower disease-free survival both in univariate analysis ( $p=0.0013$ ), and after allowing for confounding factors such as tumor size and grade, blood levels of alpha-fetoprotein and presence of microvascular invasion $[\mathrm{HR}=0.68(95 \%$ CI $0.54-0.86), p=0.0015)]$. In addition, arterial blood flow maintenance was accompanied by lessened hepatocellular injury and liver function at postoperative day one, three, and seven [65]. Of note, tumor localization was not adjusted for, although it may affect blood loss and the risk of post-resection recurrence. In other words, it could be argued that surgeons tend to apply vascular control procedures in face of more difficult cases, which, besides being at increased risk of surgical bleeding, probably also carry an increased risk of cancer recurrence.

Although more robust data are needed, altogether, these findings suggest that surgical innovation may allow a blunting in pedicle clamping-induced I/R lesions and help achieving better oncological outcomes.

\section{Liver Transplantation}

I/R lesions, including organ injury caused by small-for-size livers, have been repeatedly observed to be associated with poor oncological outcomes in liver transplantation, and a recent meta-analysis identified 16 studies comparing living-donor liver transplantation (LDLT, a surrogate for lower graft size) with deceased-donor liver transplantation (DDLT) [66]. Statistical pooling of disease-free survival revealed an aggregate HR of 1.59 (95 \% CI 1.02-2.49; $p=0.041$ ), showing that LDLT was significantly associated with higher post-transplant $\mathrm{HCC}$ recurrence rates. In contrast, pooled overall survival was not different between LDLT and DDLT $[\mathrm{HR}=0.97 \quad$ (95 \% CI $0.73-1.27$; $p=0.808)$ ] [66]. Noteworthy is that there is a lack of evidence as to whether common markers of I/R injury (e.g., cold and warm ischemia time, presence of graft steatosis, donor age) are correlated with the risk of post-transplant tumor recurrence. Recently, Mathur et al. [67] have shown that increasing BMI was associated with a significantly higher and earlier HCC recurrence rate. Looking at the extreme scenario of marginal grafts such as DCD, Jay et al. [68] and Croome et al. [69] pointed out that the use of DCD donors was associated with a synergistically increased death rate after transplantation in HCC-bearing patients as opposed to patients without HCC. However, HCC patients undergoing liver transplantation may die of other reasons than tumor recurrence. In addition, these studies did not determine actual HCC recurrence, providing only indirect evidence of an association between donor characteristics and poor oncological. Hence, the interpretation of donation after cardiac death as a risk factor for post-transplant HCC recurrence deserves further validation in the clinical setting.

No clinical liver transplantation studies evaluating the effectiveness of strategies blunting I/R injury as a means of achieving improved oncological outcomes could be identified.

\section{Mechanisms}

\section{Underlying Parenchymal Abnormalities}

The hepatic tissue does not systematically react to the ischemic insult in the same way. Owing to the diverse clinical situations underlying liver cirrhosis and HCC (hepatitis B, C, alcohol, steatohepatitis) and to the complex therapeutic strategies (chemotherapy, radiofrequency ablation, transarterial chemoembolization) potentially applied to patients before liver surgery, parenchymal abnormalities appear to be involved in the post-surgical course of patients undergoing either hepatectomy or liver transplantation [22, 70, 71]. Fatty livers show alterations in mitochondrial metabolism as well as increased production of insulin-like growth factor 1, which promotes cell growth and proliferation, and inhibits apoptosis [17, 72-74]. These pathological changes could in turn stimulate carcinogenesis, making steatosis a favorable microenvironment for tumor growth. In this mind, the Utrecht group demonstrated that aging (12-13 months) and steatosis, as induced by feeding mice with a high-fat diet, intensified the I/Rinduced outgrowth of colorectal adenocarcinoma micrometastases as compared to lean animals exposed to I/R injury [39]. Another group went on investigating the relationship between steatosis and hepatic tumor growth and observed spontaneous hepatic dysplastic tumor occurrence as early as 9 months after the introduction of a high-fat diet [75]. The number and size of tumor nodules increased over time, and at 20 months after high-fat diet introduction, all animals developed tumor nodules. In contrast, no tumor was detected (neither after gross or histological assessment) in mice maintained on regular diet at the same time points. The same group confirmed the role of a steatotic microenvironment at favouring hepatic metastases implantation upon observation of a significantly greater hepatic tumor load in those animals allocated to high-fat diet as compared to control, 21 days after tumor cell injection in the portal system [75]. From a clinical standpoint, Hamady et al. reported the results of a large cohort $(n=2,715)$ of patients undergoing hepatectomy for colorectal liver metastases, comparing livers with or without steatosis (defined as a diffuse accumulation of fat droplets affecting more than $5 \%$ of hepatocytes) with regard to hepatic disease-free survival [76]. After adjusting for relevant 
confounders, the Cox proportional model showed a significantly higher recurrence rate at 1,3 , and 5 years postsurgery in the steatosis versus non-steatosis group (79.6, 59.2 , and $52.9 \%$ vs. $85.3,67.1$, and $61.9 \%$, respectively, $p<0.001)$. These results were confirmed in a matched propensity score analysis. Although providing novel insights into the debate of the oncological impact of fatty liver disease, this recent study lacks a formal histological assessment of the precise nature of fatty infiltration, which can diverge considerably (e.g., macro- vs. microvesicular steatosis) and differently affect post-surgical outcomes [22].

\section{Microcirculatory Lesions, Tissue Hypoxia, and Angiogenesis}

Microcirculatory dysfunction has been repeatedly reported to constitute a source of hypoxia and tissue disruption in the setting of I/R injury (Fig. 1) [77, 78]. Sustained hypoxia to the liver promotes hypoxia-inducible factor
(HIF-) $1 \alpha$, which acts as a cell survival factor, and is a promoter of tumor cell proliferation, angiogenesis, and cell migration [79-81]. Van der Bilt et al. [39, 62, 82] demonstrated on several occasions that, after $\mathrm{I} / \mathrm{R}$ injury, accelerated tumor growth predominantly surrounded necrotic parenchyma and that I/R-mediated tumor growth was linked to increased parenchymal HIF-1 $\alpha$ expression [82]. Moreover, prevention of ischemia-induced microcirculation disturbance with L-arginine (an enhancer of endothelial NO synthesis) reduced the outgrowth of micrometastases by minimizing tissue hypoxia and avoiding HIF-1 $\alpha$ stabilization [82]. Nijkamp et al. [56, 83] have shown that I/R-mediated tumor outgrowth was also portended by Fas-Fas ligand interactions, which appear to be pivotal in the process of necrotic tissue formation.

Several reports have shown that the ischemic liver upregulates vascular endothelial growth factor (VEGF) expression, a well-known angiogenic factor. In the context of liver surgery for cancer, surgical stress and $\mathrm{I} / \mathrm{R}$ injury appear to stimulate VEGF expression, which could foster

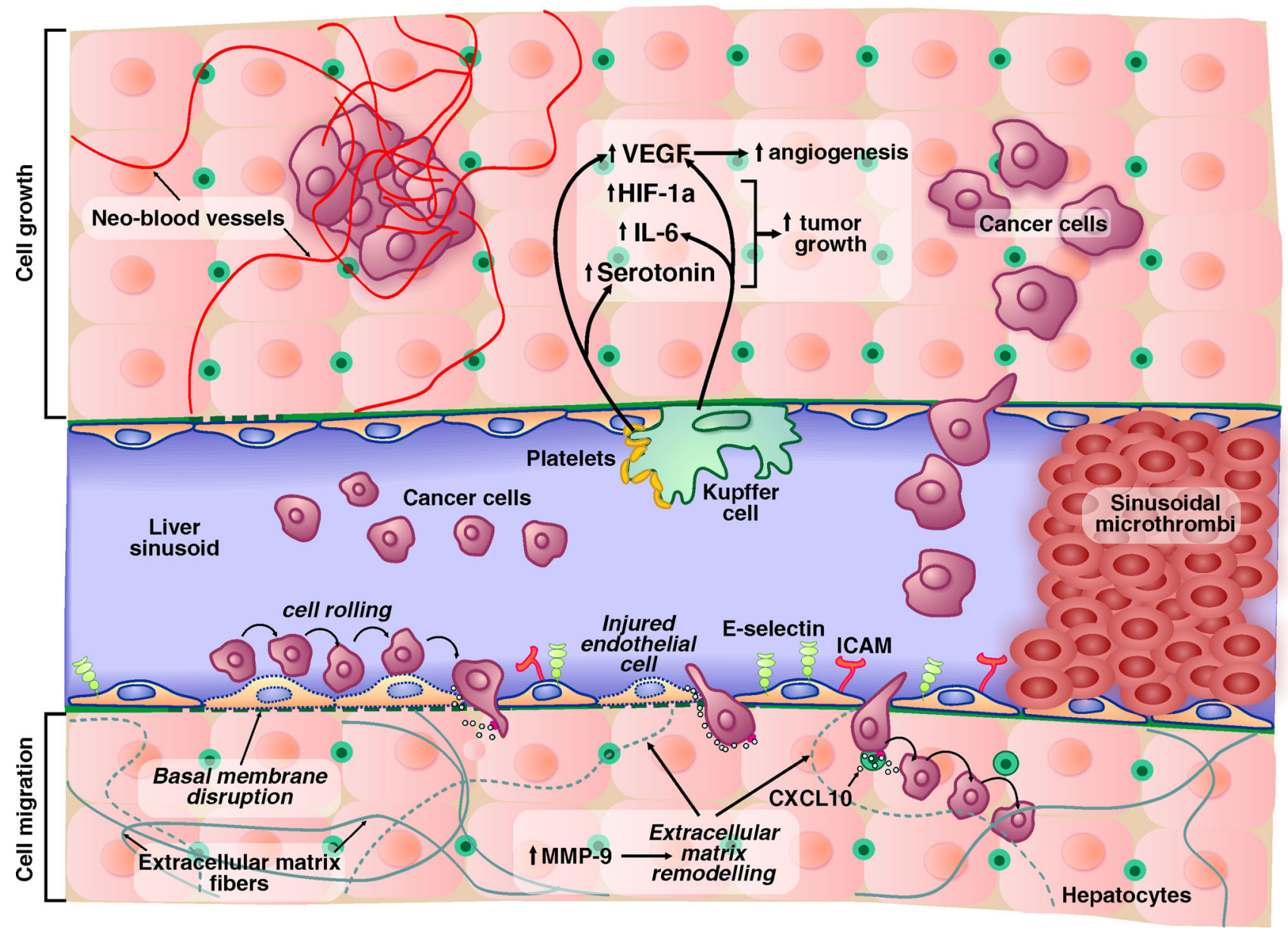

Fig. 1 Explored mechanisms suggesting a role between liver ische$\mathrm{mia} /$ reperfusion injury and cancer cell migration (bottom) and growth (top). VEGF vascular endothelial growth factor, HIF hypoxia- inducible factor, $I L$ interleukin, $M M P$ matrix metalloproteinase, $I C A M$ intercellular adhesion molecule, $C X C L$ [chemokine $(\mathrm{C}-\mathrm{X}-\mathrm{C}$ motif) ligand] 
tumor growth through two main mechanisms. First, there is overwhelming evidence that VEGF assumes a pivotal role in tumor angiogenesis, and in the liver, I/R-mediated VEGF upregulation leads to improved tumor vascularization. Second, VEGF receptor is overexpressed on several types of cancer cells, including colorectal cancer [36, 84, 85] and hepatocellular carcinoma cells [86], suggesting an autocrine effect of VEGF on tumor cells expressing VEGF receptors. Similarly, novel functions of VEGF have been reported in various oncological settings, including the promotion of cancer cell survival [87-89] and migration [90].

\section{Cell Adhesion, Migration, and Extracellular Matrix Remodeling}

Leukocyte adhesion molecules, which are expressed upon the activation of inflammatory pathways, have been repeatedly correlated with progression of several types of carcinoma [91-93]. In a rat adenocarcinoma metastasis model, Kurata et al. [32] showed the expression of E-selectin to be significantly increased after I/R injury, peaking at $120 \mathrm{~min}$ after reperfusion. E-selectin expression correlated with ischemia duration and its expression in ischemic tissue was accompanied by a higher number of metastatic nodules. Intriguingly, the administration of antithrombin reversed this IR/mediated increased tumor burden by inhibiting TNF- $\alpha$ secretion and by blunting the expression of E-selectin. Furthermore, antithrombin-KO mice developed significantly less metastatic nodules compared to wild-type animals. Altogether, these observations highlight the relevance of microvasculature ultrastructure in the process of tumor cell trafficking and migration. Although its clinical effectiveness has been questioned when administered to critically ill patients [94], antithrombin therapy may represent a potential option, and further investigation is needed.

Chemokines are critical mediators involved in the process of I/R injury [95-97]. On top of their chemotactic activity on inflammatory cells, chemokines and their receptors are involved in cancer cell invasive potential [98100]. Man and colleagues demonstrated that CXCL10 (interferon $\gamma$-induced protein 10) was overexpressed in small-for-size livers and that upon CXCL10 stimulation, hepatocellular carcinoma cells displayed pro-migration morphological changes such as stress fiber and lamellipodia formation [53]. In addition to these phenotypical changes, CXCL10 directly impacted on cell motility as assessed in an in vitro wound healing assay [53] and appeared as pivotal with regard to endothelial progenitor cell migration [101].

There is a body of evidence supporting the role of extracellular matrix remodeling in promoting tumor invasiveness and metastasis [102]. In particular, matrix metalloproteinases (MMPs) have been shown to be crucial mediators of the invasive potential of several cancers, including colon adenocarcinoma [103] and HCC [104]. Previous research indicates that extracellular matrix remodeling arising in the setting of $\mathrm{I} / \mathrm{R}$ injury is mediated by an increase in MMP-9 expression [105]. Nicoud et al. demonstrated in a series of elegant experiments that MMP9 upregulation after I/R injury promoted the outgrowth of colorectal carcinoma micrometastases and that doxycycline-mediated MMP inhibition, as well as MMP-9 genetic silencing, reversed the I/R-related accelerated tumor growth. Of note, these observations lack confirmatory evidence from human studies, as Xia et al. [58] did not report differences in terms of liver tissue mRNA and blood levels of MMP-2, MMP-9, and E-selectin between patients undergoing pedicle clamping or not.

\section{Conclusion and Perspective}

Although data accumulated from preclinical models uniformly point out liver quality as a determinant of cancer cell implantation and growth, the evidence gathered from the clinical setting is still limited and ongoing research in the form of prospective randomized trials should shed light on this so far unresolved issue. In the meantime, it appears as reasonable to implement therapeutic approaches to minimize I/R injury, especially in patients with more advanced tumor, given their potentially higher pool of circulating cancer cells. Several therapeutic interventions such as ischemic pre-conditioning [106], intravenous corticosteroids [4], prostaglandin E [107], and volatile anesthetics [108] have been shown to improve ischemiareperfusion, and their specific impact on oncological outcomes should be assessed. In this regard, we have shown that graft reperfusion prior to retrieval reduces the HCC growth in a rat liver transplantation model [55]. Moreover, neoadjuvant and downstaging strategies appear justified, provided they do not harmfully delay the access to definitive therapy. Long-term oncological outcomes should be assessed when comparing various vascular inflow control procedures and conclusions of RCTs examining early morbidity, and post-operative hepatocellular damage [109] may not apply to delayed cancer recurrence. Although there is better understanding of the interaction between I/R injury and tumor recurrence, biological mechanisms underlying these observations remain largely unresolved. Thus, future research should investigate the cell signaling pathways involved in cell survival of the injured liver in the presence of cancer.

Acknowledgments We are grateful to Mrs. Dawne Colwell for her precious input in graphic design. This study was supported by the 
Ligue genevoise contre le cancer, the Henri Dubois-Ferrière/Dinu Lipatti Foundation, and the Artères Foundation. Lorenzo Orci and Christian Toso were supported by the Swiss National Science Foundation (Grants 323530-151477, 3232230-126233).

Conflict of interest None.

\section{References}

1. Pan J, Konstas AA, Bateman B, Ortolano GA, Pile-Spellman J. Reperfusion injury following cerebral ischemia: pathophysiology, MR imaging, and potential therapies. Neuroradiology. 2007;49:93-102.

2. Collard CD, Gelman S. Pathophysiology, clinical manifestations, and prevention of ischemia-reperfusion injury. Anesthesiology. 2001;94:1133-1138.

3. Zhong H, Gao Z, Chen M, et al. Cardioprotective effect of remote ischemic postconditioning on children undergoing cardiac surgery: a randomized controlled trial. Paediatr Anaesth. 2013;23:726-733.

4. Orci LA, Toso C, Mentha G, Morel P, Majno PE. Systematic review and meta-analysis of the effect of perioperative steroids on ischaemia-reperfusion injury and surgical stress response in patients undergoing liver resection. Br J Surg. 2013;100: 600-609.

5. Zhai Y, Petrowsky H, Hong JC, Busuttil RW, Kupiec-Weglinski JW. Ischaemia-reperfusion injury in liver transplantation-from bench to bedside. Nat Rev Gastroenterol Hepatol. 2013;10: 79-89.

6. van der Vliet JA, Warle MC. The need to reduce cold ischemia time in kidney transplantation. Curr Opin Organ Transplant. 2013;18:174-178.

7. Bahde R, Spiegel HU. Hepatic ischaemia-reperfusion injury from bench to bedside. Br J Surg. 2010;97:1461-1475.

8. Powell JT, Tsapepas DS, Martin ST, Hardy MA, Ratner LE. Managing renal transplant ischemia reperfusion injury: novel therapies in the pipeline. Clin Transplant. 2013;27:484-491.

9. de Boer MT, Molenaar IQ, Porte RJ. Impact of blood loss on outcome after liver resection. Dig Surg. 2007;24:259-264.

10. Kooby DA, Stockman J, Ben-Porat L, et al. Influence of transfusions on perioperative and long-term outcome in patients following hepatic resection for colorectal metastases. Ann Surg. 2003;237:860-869. (discussion 869-870).

11. Katz SC, Shia J, Liau KH, et al. Operative blood loss independently predicts recurrence and survival after resection of hepatocellular carcinoma. Ann Surg. 2009;249:617-623.

12. Gurusamy KS, Naik P, Abu-Amara M, Fuller B, Davidson BR. Techniques of flushing and reperfusion for liver transplantation. Cochrane Database Syst Rev. 2012;3:CD007512.

13. Mullhaupt B, Dimitroulis D, Gerlach JT, Clavien PA. Hot topics in liver transplantation: organ allocation-extended criteria donor-living donor liver transplantation. J Hepatol. 2008;48: S58-S67.

14. Pascher A, Neuhaus P. Biliary complications after deceaseddonor orthotopic liver transplantation. J Hepatobiliary Pancreat Surg. 2006;13:487-496.

15. Jay CL, Lyuksemburg V, Ladner DP, et al. Ischemic cholangiopathy after controlled donation after cardiac death liver transplantation: a meta-analysis. Ann Surg. 2011;253:259-264.

16. Clavien PA, Petrowsky H, DeOliveira ML, Graf R. Strategies for safer liver surgery and partial liver transplantation. $N$ Engl $J$ Med. 2007;356:1545-1559.

17. Marsman HA, Heger M, Kloek JJ, Nienhuis SL, ten Kate FJ, van Gulik TM. Omega-3 fatty acids reduce hepatic steatosis and consequently attenuate ischemia-reperfusion injury following partial hepatectomy in rats. Dig Liver Dis. 2011;43:984-990.

18. Selzner N, Selzner M, Jochum W, Clavien PA. Ischemic preconditioning protects the steatotic mouse liver against reperfusion injury: an ATP dependent mechanism. J Hepatol. 2003;39:55-61.

19. Serafin A, Rosello-Catafau J, Prats N, Xaus C, Gelpi E, Peralta C. Ischemic preconditioning increases the tolerance of fatty liver to hepatic ischemia-reperfusion injury in the rat. Am J Pathol. 2002;161:587-601.

20. Selzner N, Selzner M, Jochum W, Amann-Vesti B, Graf R, Clavien PA. Mouse livers with macrosteatosis are more susceptible to normothermic ischemic injury than those with microsteatosis. J Hepatol. 2006;44:694-701.

21. Selzner M, Selzner N, Jochum W, Graf R, Clavien PA. Increased ischemic injury in old mouse liver: an ATP-dependent mechanism. Liver Transpl. 2007;13:382-390.

22. Dutkowski P, Schlegel A, Slankamenac K, et al. The use of fatty liver grafts in modern allocation systems: risk assessment by the balance of risk (BAR) score. Ann Surg. 2012;256:861-868. (discussion 868-869).

23. Nocito A, El-Badry AM, Clavien PA. When is steatosis too much for transplantation? J Hepatol. 2006;45:494-499.

24. Guller U, Zajac P, Schnider A, et al. Disseminated single tumor cells as detected by real-time quantitative polymerase chain reaction represent a prognostic factor in patients undergoing surgery for colorectal cancer. Ann Surg. 2002;236:768-775. (discussion 775-766).

25. Yamaguchi K, Takagi Y, Aoki S, Futamura M, Saji S. Significant detection of circulating cancer cells in the blood by reverse transcriptase-polymerase chain reaction during colorectal cancer resection. Ann Surg. 2000;232:58-65.

26. Anasagasti MJ, Alvarez A, Martin JJ, Mendoza L, VidalVanaclocha F. Sinusoidal endothelium release of hydrogen peroxide enhances very late antigen-4-mediated melanoma cell adherence and tumor cytotoxicity during interleukin-1 promotion of hepatic melanoma metastasis in mice. Hepatology. 1997;25:840-846.

27. Higashiyama A, Watanabe H, Okumura K, Yagita H. Involvement of tumor necrosis factor alpha and very late activation antigen 4/vascular cell adhesion molecule 1 interaction in surgical-stress-enhanced experimental metastasis. Cancer Immunol Immunother (CII). 1996;42:231-236.

28. Vidal-Vanaclocha F, Alvarez A, Asumendi A, Urcelay B, Tonino P, Dinarello CA. Interleukin 1 (IL-1)-dependent melanoma hepatic metastasis in vivo; increased endothelial adherence by IL-1-induced mannose receptors and growth factor production in vitro. J Natl Cancer Inst. 1996;88:198-205.

29. Chu MJ, Hickey AJ, Phillips AR, Bartlett AS. The impact of hepatic steatosis on hepatic ischemia-reperfusion injury in experimental studies: a systematic review. BioMed Res Int. 2013;2013:192029.

30. Murphy P, Alexander P, Senior PV, Fleming J, Kirkham N, Taylor I. Mechanisms of organ selective tumour growth by bloodborne cancer cells. Br J Cancer. 1988;57:19-31.

31. Robinson KP, Hoppe E. The development of blood-borne metastases. Effect of local trauma and ischemia. Arch Surg. 1962;85:720-724.

32. Kurata M, Okajima K, Kawamoto T, Uchiba M, Ohkohchi N. Antithrombin reduces reperfusion-induced hepatic metastasis of colon cancer cells. World J Gastroenterol. 2006;12:60-65.

33. Nicoud IB, Jones CM, Pierce JM, et al. Warm hepatic ischemiareperfusion promotes growth of colorectal carcinoma micrometastases in mouse liver via matrix metalloproteinase-9 induction. Cancer Res. 2007;67:2720-2728.

34. Man $\mathrm{K}, \mathrm{Ng} \mathrm{KT}$, Lo CM, et al. Ischemia-reperfusion of small liver remnant promotes liver tumor growth and metastases- 
activation of cell invasion and migration pathways. Liver Transpl. 2007;13:1669-1677.

35. Doi K, Horiuchi T, Uchinami M, et al. Neutrophil elastase inhibitor reduces hepatic metastases induced by ischaemia-reperfusion in rats. Eur J Surg. 2002;168:507-510.

36. Tamagawa K, Horiuchi T, Uchinami M, et al. Hepatic ischemiareperfusion increases vascular endothelial growth factor and cancer growth in rats. J Surg Res. 2008;148:158-163.

37. Yoshida M, Horiuchi T, Uchinami M, et al. Intermittent hepatic ischemia-reperfusion minimizes liver metastasis in rats. $J$ Surg Res. 2003;111:255-260.

38. Yoshimoto K, Tajima H, Ohta T, et al. Increased E-selectin in hepatic ischemia-reperfusion injury mediates liver metastasis of pancreatic cancer. Oncol Rep. 2012;28:791-796.

39. van der Bilt JD, Kranenburg O, Borren A, van Hillegersberg R, Borel Rinkes IH. Ageing and hepatic steatosis exacerbate ischemia/reperfusion-accelerated outgrowth of colorectal micrometastases. Ann Surg Oncol. 2008;15:1392-1398.

40. Doi K, Horiuchi T, Uchinami M, et al. Hepatic ischemiareperfusion promotes liver metastasis of colon cancer. J Surg Res. 2002;105:243-247.

41. Fisher B, Fisher ER. Experimental studies of factors influencing hepatic metastases. III. Effect of surgical trauma with special reference to liver injury. Ann Surg. 1959;150:731-744.

42. Ichihashi H, Mabuchi H, Suenaga M, Kondo T. Liver regeneration and tumor growth in the rat after partial hepatectomy. Jpn J Surg. 1984;14:510-514.

43. Ikeda Y, Matsumata T, Takenaka K, Sasaki O, Soejima K, Sugimachi K. Preliminary report of tumor metastasis during liver regeneration after hepatic resection in rats. Eur J Surg Oncol. 1995;21:188-190.

44. Isbert C, Boerner A, Ritz JP, Schuppan D, Buhr HJ, Germer CT. In situ ablation of experimental liver metastases delays and reduces residual intrahepatic tumour growth and peritoneal tumour spread compared with hepatic resection. Br J Surg. 2002;89:1252-1259.

45. Mizutani J, Hiraoka T, Yamashita R, Miyauchi Y. Promotion of hepatic metastases by liver resection in the rat. Br J Cancer. 1992;65:794-797.

46. Picardo A, Karpoff HM, Ng B, Lee J, Brennan MF, Fong Y. Partial hepatectomy accelerates local tumor growth: potential roles of local cytokine activation. Surgery. 1998;124:57-64.

47. Schindel DT, Grosfeld JL. Hepatic resection enhances growth of residual intrahepatic and subcutaneous hepatoma, which is inhibited by octreotide. J Pediatr Surg. 1997;32:995-997. (discussion 997-998).

48. de Jong KP, Slooff MJ, de Vries EG, Brouwers MA, Terpstra OT. Effect of partial liver resection on tumour growth. $J$ Hepatol. 1996;25:109-121.

49. Schnitzbauer AA, Lang SA, Goessmann H, et al. Right portal vein ligation combined with in situ splitting induces rapid left lateral liver lobe hypertrophy enabling 2-staged extended right hepatic resection in small-for-size settings. Ann Surg. 2012;255:405-414.

50. Dahm F, Georgiev P, Clavien PA. Small-for-size syndrome after partial liver transplantation: definition, mechanisms of disease and clinical implications. Am J Transplant. 2005;5:2605-2610.

51. Man K, Lo CM, Ng IO, et al. Liver transplantation in rats using small-for-size grafts: a study of hemodynamic and morphological changes. Arch Surg. 2001;136:280-285.

52. Oya H, Sato Y, Yamamoto S, et al. Surgical procedures for decompression of excessive shear stress in small-for-size living donor liver transplantation-new hepatic vein reconstruction. Transpl Proc. 2005;37:1108-1111.

53. Man K, Shih KC, Ng KT, et al. Molecular signature linked to acute phase injury and tumor invasiveness in small-for-size liver grafts. Ann Surg. 2010;251:1154-1161.
54. Busuttil RW, Tanaka K. The utility of marginal donors in liver transplantation. Liver Transpl. 2003;9:651-663.

55. Oldani G, Crowe LA, Orci LA, et al. Pre-retrieval reperfusion decreases cancer recurrence after rat ischemic liver graft transplantation. J Hepatol. 2014 (Epub ahead of print). doi:10.1016/j. jhep.2014.03.036.

56. Nijkamp MW, Hoogwater FJ, Steller EJ, et al. CD95 is a key mediator of invasion and accelerated outgrowth of mouse colorectal liver metastases following radiofrequency ablation. $J$ Hepatol. 2010;53:1069-1077.

57. Giuliante F, Ardito F, Pulitano C, et al. Does hepatic pedicle clamping affect disease-free survival following liver resection for colorectal metastases? Ann Surg. 2010;252:1020-1026.

58. Xia F, Lau WY, Xu Y, Wu L, Qian C, Bie P. Does hepatic ischemia-reperfusion injury induced by hepatic pedicle clamping affect survival after partial hepatectomy for hepatocellular carcinoma? World J Surg. 2013;37:192-201.

59. Ferrero A, Russolillo N, Vigano L, Lo Tesoriere R, Muratore A, Capussotti L. Does Pringle maneuver affect survival in patients with colorectal liver metastases? World J Surg. 2010;34: 2418-2425.

60. Matsuda A, Miyashita M, Matsumoto S, et al. Hepatic pedicle clamping does not worsen survival after hepatic resection for colorectal liver metastasis: results from a systematic review and meta-analysis. Ann Surg Oncol. 2013;20:3771-3778.

61. Xiaobin F, Shuguo Z, Jian Z, et al. Effect of the pringle maneuver on tumor recurrence of hepatocellular carcinoma after curative resection (EPTRH): a randomized, prospective, controlled multicenter trial. BMC Cancer. 2012;12:340.

62. van der Bilt JD, Kranenburg O, Nijkamp MW, et al. Ischemia/ reperfusion accelerates the outgrowth of hepatic micrometastases in a highly standardized murine model. Hepatology. 2005;42:165-175.

63. Wong KH, Hamady ZZ, Malik HZ, Prasad R, Lodge JP, Toogood GJ. Intermittent Pringle manoeuvre is not associated with adverse long-term prognosis after resection for colorectal liver metastases. Br J Surg. 2008;95:985-989.

64. Makino I, Chijiiwa K, Kondo K, Ohuchida J, Kai M. Prognostic benefit of selective portal vein occlusion during hepatic resection for hepatocellular carcinoma. Surgery. 2005;137:626-631.

65. Yang Y, Fu SY, Lau WY, et al. Selective main portal vein clamping to minimize the risk of recurrence after curative liver resection for hepatocellular carcinoma. Hepatogastroenterology. 2012;59:1560-1565.

66. Grant RC, Sandhu L, Dixon PR, Greig PD, Grant DR, McGilvray ID. Living vs. deceased donor liver transplantation for hepatocellular carcinoma: a systematic review and metaanalysis. Clin Transplant. 2013;27:140-147.

67. Mathur A, Franco ES, Leone JP, et al. Obesity portends increased morbidity and earlier recurrence following liver transplantation for hepatocellular carcinoma. HPB (Oxford). 2013;15:504-510.

68. Jay C, Ladner D, Wang E, et al. A comprehensive risk assessment of mortality following donation after cardiac death liver transplant-an analysis of the national registry. J Hepatol. 2011;55:808-813.

69. Croome KP, Wall W, Chandok N, Beck G, Marotta P, Hernandez-Alejandro R. Inferior survival in liver transplant recipients with hepatocellular carcinoma receiving donation after cardiac death liver allografts. Liver Transpl. 2013;19:1214-1223.

70. Fong Y, Bentrem DJ. CASH (chemotherapy-associated steatohepatitis) costs. Ann Surg. 2006;243:8-9.

71. Vauthey JN, Pawlik TM, Ribero D, et al. Chemotherapy regimen predicts steatohepatitis and an increase in 90-day mortality after surgery for hepatic colorectal metastases. $J$ Clin Oncol. 2006;24:2065-2072. 
72. Hribal ML, Procopio T, Petta S, et al. Insulin-like growth factorI, inflammatory proteins, and fibrosis in subjects with nonalcoholic fatty liver disease. J Clin Endocrinol Metab. 2013;98: E304-E308.

73. Ijaz S, Yang W, Winslet MC, Seifalian AM. Impairment of hepatic microcirculation in fatty liver. Microcirculation. 2003;10: 447-456

74. Fromenty B, Berson A, Pessayre D. Microvesicular steatosis and steatohepatitis: role of mitochondrial dysfunction and lipid peroxidation. J Hepatol. 1997;26:13-22.

75. VanSaun MN, Lee IK, Washington MK, Matrisian L, Gorden DL. High fat diet induced hepatic steatosis establishes a permissive microenvironment for colorectal metastases and promotes primary dysplasia in a murine model. Am J Pathol. 2009; 175:355-364.

76. Hamady ZZ, Rees M, Welsh FK, et al. Fatty liver disease as a predictor of local recurrence following resection of colorectal liver metastases. Br J Surg. 2013;100:820-826.

77. Pannen BH, Al-Adili F, Bauer M, Clemens MG, Geiger KK. Role of endothelins and nitric oxide in hepatic reperfusion injury in the rat. Hepatology. 1998;27:755-764.

78. Vollmar B, Glasz J, Leiderer R, Post S, Menger MD. Hepatic microcirculatory perfusion failure is a determinant of liver dysfunction in warm ischemia-reperfusion. Am J Pathol. 1994; 145:1421-1431.

79. Carmeliet P, Dor Y, Herbert JM, et al. Role of HIF-1alpha in hypoxia-mediated apoptosis, cell proliferation and tumour angiogenesis. Nature. 1998;394:485-490.

80. Ryan HE, Poloni M, McNulty W, et al. Hypoxia-inducible factor-1alpha is a positive factor in solid tumor growth. Cancer Res. 2000;60:4010-4015.

81. Stoeltzing O, McCarty MF, Wey JS, et al. Role of hypoxiainducible factor 1alpha in gastric cancer cell growth, angiogenesis, and vessel maturation. J Natl Cancer Inst. 2004;96:946-956.

82. van der Bilt JD, Soeters ME, Duyverman AM, et al. Perinecrotic hypoxia contributes to ischemia/reperfusion-accelerated outgrowth of colorectal micrometastases. Am J Pathol. 2007;170: 1379-1388.

83. Nijkamp MW, Hoogwater FJ, Govaert KM, et al. A role for CD95 signaling in ischemia/reperfusion-induced invasion and outgrowth of colorectal micrometastases in mouse liver. J Surg Oncol. 2011;104:198-204.

84. Fan F, Wey JS, McCarty MF, et al. Expression and function of vascular endothelial growth factor receptor-1 on human colorectal cancer cells. Oncogene. 2005;24:2647-2653.

85. Witte D, Thomas A, Ali N, Carlson N, Younes M. Expression of the vascular endothelial growth factor receptor-3 (VEGFR-3) and its ligand VEGF-C in human colorectal adenocarcinoma. Anticancer Res. 2002;22:1463-1466.

86. Li T, Zhu Y, Qin CY, et al. Expression and prognostic significance of vascular endothelial growth factor receptor 1 in hepatocellular carcinoma. J Clin Pathol. 2012;65:808-814.

87. Bates RC, Goldsmith JD, Bachelder RE, et al. Flt-1-dependent survival characterizes the epithelial-mesenchymal transition of colonic organoids. Current biology (CB). 2003;13:1721-1727.

88. Chung J, Bachelder RE, Lipscomb EA, Shaw LM, Mercurio AM. Integrin (alpha 6 beta 4 ) regulation of eIF-4E activity and VEGF translation: a survival mechanism for carcinoma cells. $J$ Cell Biol. 2002;158:165-174.

89. Masood R, Cai J, Zheng T, Smith DL, Hinton DR, Gill PS. Vascular endothelial growth factor (VEGF) is an autocrine growth factor for VEGF receptor-positive human tumors. Blood. 2001;98:1904-1913.

90. Mercurio AM, Lipscomb EA, Bachelder RE. Non-angiogenic functions of VEGF in breast cancer. J Mammary Gland Biol Neoplasia. 2005;10:283-290.
91. Alexiou D, Karayiannakis AJ, Syrigos KN, et al. Serum levels of E-selectin, ICAM-1 and VCAM-1 in colorectal cancer patients: correlations with clinicopathological features, patient survival and tumour surgery. Eur J Cancer. 2001;37:2392-2397.

92. King JA, Ofori-Acquah SF, Stevens T, Al-Mehdi AB, Fodstad $\mathrm{O}$, Jiang WG. Activated leukocyte cell adhesion molecule in breast cancer: prognostic indicator. Breast Cancer Res (BCR). 2004;6:R478-R487.

93. Yoong KF, McNab G, Hubscher SG, Adams DH. Vascular adhesion protein-1 and ICAM-1 support the adhesion of tumorinfiltrating lymphocytes to tumor endothelium in human hepatocellular carcinoma. J Immunol. 1998;160:3978-3988.

94. Afshari A, Wetterslev J, Brok J, Møller AM. Antithrombin III for critically ill patients. Cochrane Database Syst Rev. 2008; CD005370. doi:10.1002/14651858.CD005370.pub2.

95. Colletti LM, Kunkel SL, Walz A, et al. The role of cytokine networks in the local liver injury following hepatic ischemia/ reperfusion in the rat. Hepatology. 1996;23:506-514.

96. Lentsch AB, Kato A, Yoshidome H, McMasters KM, Edwards MJ. Inflammatory mechanisms and therapeutic strategies for warm hepatic ischemia/reperfusion injury. Hepatology. 2000;32:169-173.

97. Zhai Y, Shen XD, Gao F, et al. CXCL10 regulates liver innate immune response against ischemia and reperfusion injury. Hepatology. 2008;47:207-214.

98. Huang F, Geng XP. Chemokines and hepatocellular carcinoma. World J Gastroenterol (WJG). 2010;16:1832-1836.

99. Schimanski CC, Bahre R, Gockel I, et al. Dissemination of hepatocellular carcinoma is mediated via chemokine receptor CXCR4. Br J Cancer. 2006;95:210-217.

100. Zipin-Roitman A, Meshel T, Sagi-Assif O, et al. CXCL10 promotes invasion-related properties in human colorectal carcinoma cells. Cancer Res. 2007;67:3396-3405.

101. Ling CC, $\mathrm{Ng} \mathrm{KT}$, Shao Y, et al. Post-transplant endothelial progenitor cell mobilization via CXCL10/CXCR3 signaling promotes liver tumor growth. J Hepatol. 2014;60:103-109.

102. Lu P, Weaver VM, Werb $Z$. The extracellular matrix: a dynamic niche in cancer progression. J Cell Biol. 2012;196:395-406.

103. Zucker S, Vacirca J. Role of matrix metalloproteinases (MMPs) in colorectal cancer. Cancer Metastasis Rev. 2004;23:101-117.

104. Egeblad M, Werb Z. New functions for the matrix metalloproteinases in cancer progression. Nat Rev Cancer. 2002;2: 161-174.

105. Chen CF, Leu FJ, Chen HI, Wang D. Oxygen radicals and matrix metalloproteinases mediate reperfusion liver injury. Transpl Proc. 2005;37:4547-4549.

106. de Rougemont O, Lehmann K, Clavien PA. Preconditioning, organ preservation, and postconditioning to prevent ischemiareperfusion injury to the liver. Liver Transpl. 2009;15: $1172-1182$.

107. Sugawara Y, Kubota K, Ogura T, et al. Protective effect of prostaglandin E1 against ischemia/reperfusion-induced liver injury: results of a prospective, randomized study in cirrhotic patients undergoing subsegmentectomy. J Hepatol. 1998;29: 969-976.

108. Beck-Schimmer B, Breitenstein S, Urech S, et al. A randomized controlled trial on pharmacological preconditioning in liver surgery using a volatile anesthetic. Ann Surg. 2008;248:909-918.

109. van den Broek MA, Bloemen JG, Dello SA, van de Poll MC, Olde Damink SW, Dejong CH. Randomized controlled trial analyzing the effect of 15 or $30 \mathrm{~min}$ intermittent Pringle maneuver on hepatocellular damage during liver surgery. $J$ Hepatol. 2011;55:337-345. 